\title{
Reúso da água como ferramenta de revitalização de uma estação de tratamento de efluentes
}

\section{Water reuse as a wastewater treatment plant revitalization tool}

\author{
Cristiano Corrêa Weber \\ Engenheiro Civil pela Universidade Federal do Rio Grande do Sul (UFRGS). Mestrando em Recursos Hídricos e Saneamento Ambiental do Instituto de \\ Pesquisas Hidráulicas da UFRGS. Supervisor de Meio Ambiente da Trombini Industrial S/A

\section{Luiz Fernando Cybis} \\ Engenheiro Civil pela UFRGS. PhD em Engenharia Sanitária e Ambiental pela University of Leeds, Inglaterra. Professor Adjunto do Instituto de Pesquisas \\ Hidráulicas da UFRGS
}

\section{Lademir Luiz Beal}

Engenheiro Químico pela Universidade Federal do Rio Grande (FURG). Doutor em Recursos Hídricos e Saneamento Ambiental pelo Instituto de Pesquisas Hidráulicas da UFRGS. Professor pesquisador do Centro de Ciências Exatas e Tecnologia da Universidade de Caxias do Sul (UCS)

\section{Resumo}

O objetivo deste artigo foi avaliar o emprego do reúso de água como ferramenta de revitalização de uma estação de tratamento de efluentes (ETE). Para comprovação em um caso real, este estudo foi desenvolvido em uma indústria de embalagens de papelão ondulado, cuja ETE apresentava baixo desempenho. A identificação de oportunidades de reúso e a simulação matemática de seu impacto sobre a ETE, por meio do balanço de cargas, apontaram para o reúso do efluente de tratamento primário como oportunidade de revitalização. Por conseguinte, esse efluente foi reusado na produção de adesivo de amido, reduzindo em mais de $60 \%$ a carga de $\mathrm{DBO}_{5}$ afluente ao processo de lodos ativados (59,14 para 22,15 kg/dia). Assim, a eficiência da ETE foi aumentada significativamente, resultando em uma redução substancial da carga despejada no corpo hídrico, com consequente observação dos padrões de lançamento estabelecidos pelo órgão ambiental.

Palavras-chave: reúso da água; tratamento de efluentes; revitalização; indústria.

\section{Abstract}

The objective of this article was to evaluate the water reuse as a wastewater treatment plant (WWTP) revitalization tool. To verify a real case, this study was developed in a corrugated paperboard package industry whose WWTP presented a low performance. The identification of reuse opportunities and the mathematic simulation of its impact on the WWTP, by the means of load balance, pointed out the reuse of primary treatment effluent as a revitalization opportunity. Therefore, this effluent was reused in starch adhesive production, reducing the affluent $\mathrm{BOD}_{5}$ into the activated sludge over 60\% (59.14 to $22.15 \mathrm{~kg} / \mathrm{day}$ ). Thus, the WWTP performance was significantly raised, resulting in a substantial reduction in contaminant load dumped into the water body with consequent observation of the standards of effluent release environmental regulation.

Keywords: water reuse; wastewater treatment; revitalization; industry.

\section{Introdução}

O reúso planejado de águas residuárias é um conceito já praticado há muitos anos em todo o mundo (CROOK, 1993) e que, no Brasil, se intensificou com a lei 9.433, de 1997, que instituiu a cobrança pelo uso dos recursos hídricos como um instrumento de gestão.

Segundo Mierzwa e Hespanhol (2005), o reúso da água corresponde ao uso de efluentes, tratados ou não, para fins benéficos, tais como irrigação, uso industrial e fins urbanos não-potáveis. A expressão "uso de efluentes" pressupõe o uso de uma água de menor qualidade que a água potável e, por isso, constitui uma alternativa mais plausível para que sejam satisfeitas demandas de água menos restritivas. Portanto, fundamentalmente em regiões que sofrem com o estresse hídrico, libera-se água de melhor qualidade para usos mais nobres e evita-se o desperdício de água (WENZEL; KNUDSEN, 2005).

Além da redução do desperdício, Rulkens (2005) cita que o reúso tem a capacidade potencial de reduzir a emissão de poluentes industriais aos corpos hídricos quando a água de reúso é incorporada 
ao produto, prevenindo a poluição. Essa prevenção pode, também, beneficiar os processos de tratamento de efluentes industriais, pois, juntamente com a água de reúso, os poluentes são incorporados ao produto, reduzindo as cargas afluentes aos processos de tratamento e prolongando sua vida útil (EPA, 2004).

Por outro lado, essa redução de cargas também pode ocasionar impactos negativos sobre os processos de tratamento de efluentes. Quando a água de reúso não sai do sistema, ou seja, ele é fechado, os poluentes têm sua concentração aumentada a cada ciclo de reúso. Desse modo, os processos de tratamento podem ser sobrecarregados e ter sua eficiência comprometida (TCHOBANOGLOUS; BURTON, 2003). Contudo, essa sobrecarga pode ser prevista e, para tanto, Mierzwa e Hespanhol (2005) propõem a modelagem matemática do sistema de reúso baseada no balanço de cargas dos poluentes. Assim, os impactos sobre o tratamento de efluentes e sobre a qualidade da água de reúso podem ser planejados antes da implantação do sistema de reúso.

Neste trabalho, o reúso da água foi estudado com o objetivo de se revitalizar a estação de tratamento de efluentes (ETE) de uma indústria de embalagens de papelão ondulado (PO) que, de acordo com seu projeto, encontrava-se subdimensionada e, portanto, não atendia aos padrões estaduais de lançamento de efluentes estabelecidos em sua licença operacional (LO) (FEPAM, 1989). O reúso foi proposto como meio para reduzir vazões e cargas poluentes afluentes à ETE.

\section{Metodologia}

A metodologia empregada neste trabalho foi baseada em Sautchúk (2004) e Mierzwa e Hespanhol (2005), modificada para

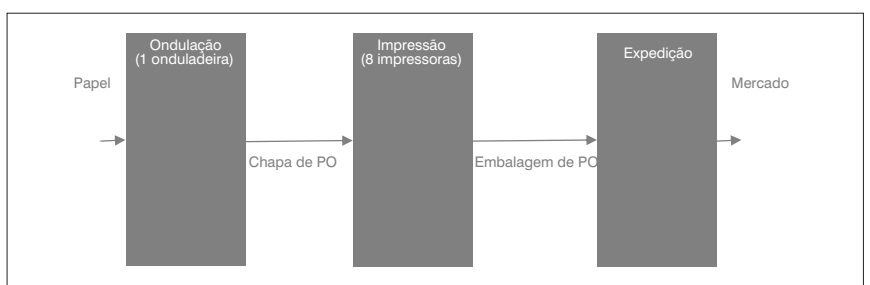

Figura 1 - Fluxograma do processo produtivo de embalagens de papelão ondulado (PO) as necessidades do estudo. Dessa forma, foi separada nas etapas de diagnóstico inicial, reúso da água e diagnóstico final.

O diagnóstico inicial foi baseado em uma análise de documentos e de dados históricos de produção e da ETE. O fluxograma da Figura 1 mostra que a produção de embalagens de PO inicia pela conformação do papel em chapas de PO que, no processo de impressão, são convertidas em embalagens de $\mathrm{PO}$ para posterior expedição. A geração de efluente industrial ocorre, principalmente, nas etapas de ondulação e de impressão durante os processos de limpeza de equipamentos. Os maiores consumos de água apresentam-se no setor de ondulação para a geração de vapor, utilizado no aquecimento do papel, e para a produção de adesivo de amido utilizado na colagem das folhas de papel constituintes das chapas de PO.

Os efluentes industriais e domésticos são tratados até o nível terciário na ETE (Figura 2). O efluente industrial, originário dos processos produtivos, é tratado por coagulação-floculação e sedimentação antes de ser misturado ao efluente doméstico no tanque pulmão (equipado com agitador). Por conseguinte, essa mistura alimenta o sistema de lodos ativados com aeração prolongada e zona anóxica para remoção de NTK (Nitrogênio Total Kjeldahl). Posteriormente, o efluente passa por filtros pressurizados de areia e carvão ativado, constituintes do tratamento terciário. A leitura das vazões é realizada por meio de leitores eletromagnéticos, com aquisição dos valores em tempo real, instalados em DOM e EF, conforme a Figura 1.

O histórico de análises foi composto por laudos, obtidos a partir de abril de 2002; a legislação observada que forneceu os limites de emissão foi a licença de operação da empresa, fundamentada na portaria $n^{\circ}$ 5/89 da FEPAM e na resolução CONAMA n 357/2005. A Tabela 1 mostra os parâmetros considerados neste estudo com os respectivos métodos analíticos de amostragem e limites de emissão.

O período no qual os limites de emissão deixaram de ser atendidos em EF foi determinado graficamente. Os valores históricos dos parâmetros da Tabela 1 e seus respectivos limites de emissão foram marcados em um gráfico tempo versus concentração, e a média móvel aritmética de quatro períodos para as concentrações foi traçada como meio de identificar a tendência de seus valores. 
Tabela 1 - Parâmetros analisados nos pontos indicados na Figura 1

$\begin{array}{lllll}\text { Parâmetro } & \text { Período de amostragem } & \text { Tipo de amostragem } & \text { Métodos analíticos (APHA, AWWA, WEF, 2005) } & \text { Limite de emissão } \\ \mathrm{DBO}_{5}\left(\mathrm{mg} \mathrm{O}_{2} / \mathrm{L}\right) & \text { Quinzenal } & \text { Composta } & \text { Winkler (titulométrico) } & 135 \\ \mathrm{DQO}\left(\mathrm{mg} \mathrm{O}_{2} / \mathrm{L}\right) & \text { Quinzenal } & \text { Composta } & \text { Refluxo aberto com } \mathrm{K}_{2} \mathrm{Cr}_{2} \mathrm{O}_{7} & 405 \\ \mathrm{NTK}(\mathrm{mg} \mathrm{NTK} / \mathrm{L}) & \text { Quinzenal } & \text { Composta } & \text { Digestão e titulométrico } & 10 \\ \mathrm{P}(\mathrm{mg} \mathrm{P} / \mathrm{L}) & \text { Quinzenal } & \text { Composta } & \text { Colorimetria do ácido ascórbico } & 1\end{array}$

$\mathrm{DBO}_{5}$ : demanda bioquímica de oxigênio; DQO: demanda química de oxigênio; NTK: Nitrogênio Total Kjeldahl; P: fósforo

Tabela 2 - Qualidade do efluente final tratado e limites máximos estabelecidos pela FEPAM para a DB05, DQ0, NTK e P

\begin{tabular}{|c|c|c|c|c|c|}
\hline & & $\mathrm{DBO}_{5}$ & DQO & NTK & $P$ \\
\hline \multirow{3}{*}{ Abril/2002 - maio/2003 } & Média & 38,38 & 152,5 & 7,69 & 0,85 \\
\hline & Desvio padrão & 14,19 & 44,44 & 3,04 & 0,53 \\
\hline & Observações & 16 & 16 & 16 & 16 \\
\hline \multirow{3}{*}{ Junho/2003 - janeiro/2007 } & Média & 163,06 & 367,53 & 35,1 & 2,31 \\
\hline & Desvio padrão & 123,67 & 238,5 & 29,51 & 2,12 \\
\hline & Observações & 72 & 72 & 72 & 72 \\
\hline \multicolumn{2}{|l|}{ Limite máximo FEPAM } & 135 & 405 & 10 & 1 \\
\hline
\end{tabular}

$\mathrm{DBO}_{5}$ : demanda bioquímica de oxigênio; DQO: demanda química de oxigênio; NTK: Nitrogênio Total Kjeldahl; P: fósforo

Ao final do diagnóstico inicial, foi analisada a eficiência de remoção dos parâmetros da Tabela 1 em cada etapa do processo de tratamento de efluentes. Esta análise considerou o período anterior e posterior à perda de controle dos limites de emissão, e as possíveis causas relacionadas à geração de efluentes foram buscadas nos dados de produção.

Essa perda de controle dos processos de tratamento demonstrava a necessidade de intervenções. O reúso da água, por ter capacidade de reduzir as cargas de contaminantes que aportam às ETE, representa uma tecnologia de prevenção da poluição que pode eliminar a necessidade de ampliação de processos de tratamento (EPA, 2004). Sob essa premissa, ele foi estudado como alternativa de revitalização da ETE.

A identificação dos potenciais pontos de consumo de água de reúso e a qualidade requerida em cada um deles deu início ao estudo. Simulando-se a alocação da água de reúso ofertada nesses pontos de consumo, pode-se estimar a correspondente redução de cargas que ocorreria na ETE e avaliar o respectivo impacto teórico sobre a eficiência dos processos de tratamento de efluentes. Para tanto, as seguintes ações foram tomadas:

- determinação dos volumes e características da água de reúso;

- modelagem matemática da ETE, baseada no balanço de cargas de demanda bioquímica de oxigênio $\left(\mathrm{DBO}_{5}\right)$, demanda química de oxigênio (DQO), Nitrogênio Total Kjeldahl (NTK) e fósforo (P); implantação do sistema de reúso.

Um diagnóstico final do estudo foi realizado após a implantação do reúso. Seu objetivo foi validar as ações tomadas, ou seja, comparar a situação pré e pós reúso da água, com vistas às mudanças esperadas para a eficiência da ETE e para as características do efluente tratado. A ferramenta adotada foi o teste de hipóteses, utilizando-se a análise estatística de Student (COSTA NETO, 2002), aplicada aos dados de caracterização dos efluentes para os três períodos deste estudo: antes

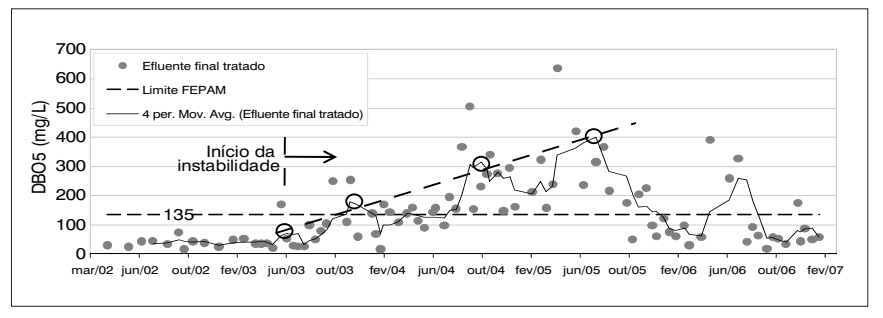

Figura 3 - Concentração da $\mathrm{DBO}_{5} \mathrm{em} \mathrm{mg/L} \mathrm{no} \mathrm{efluente} \mathrm{final} \mathrm{tratado} \mathrm{da} \mathrm{ETE}$

da ocorrência do problema, durante sua ocorrência e após o reúso da água ter sido implantado.

\section{Resultados e discussão}

\section{Diagnóstico inicial}

A evolução dos valores de $\mathrm{DBO}_{5}$ no ponto EF é apresentada na Figura 3, na qual se observa que o valor limite estabelecido pela FEPAM (135 mg/L) deixou de ser atendido a partir de junho de 2003. Os picos da média móvel de quatro períodos, aplicada aos valores de $\mathrm{DBO}_{5}$, passaram a ser crescentes a partir desse momento, conforme mostra a Figura 3. O mesmo comportamento foi observado para os valores de DQO, NTK e P, presentes no EF, demonstrando que o período identificado marca o início da instabilidade dos processos de tratamento de efluentes.

A análise estatística dos dados de concentração de poluentes em EF confirmou o não atendimento dos padrões de lançamento e a alta variabilidade dos valores a partir junho de 2003. Considerando-se os valores médios, todos os parâmetros encontravam-se fora dos limites estabelecidos pela FEPAM, com exceção da DQO. Porém, quando são considerados também os valores de desvio padrão, a DQO apresenta uma variação significativa, característica de processos instáveis (Tabela 2). 

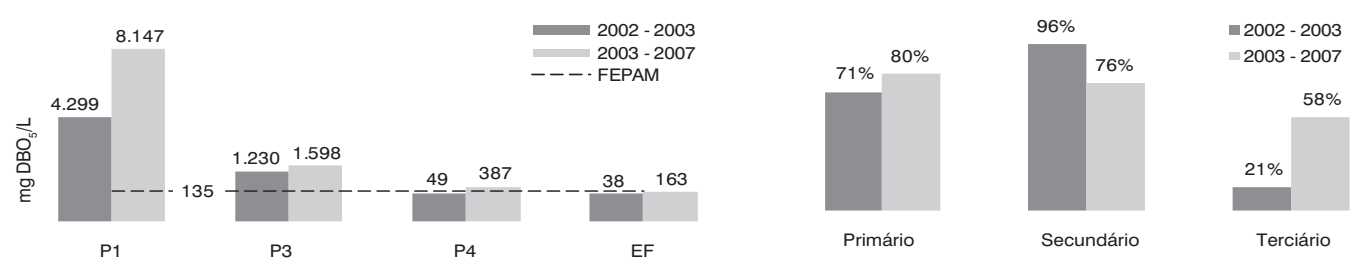

Figura 4 - Concentração de $\mathrm{DBO}_{5}$ nos pontos indicados na Figura 1 e a eficiência de remoção de $\mathrm{DBO}_{5}$ pelos processos de tratamento da ETE

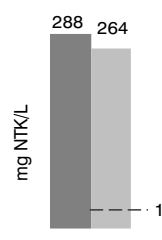

P1

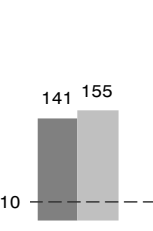

P2

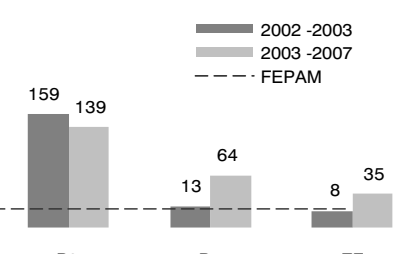

P3

P4

EF

Figura 5 - Concentração de Nitrogênio Total Kjeldahl (NTK) nos pontos indicados na Figura 1 e a eficiência de remoção de NTK pelos processos de tratamento da ETE
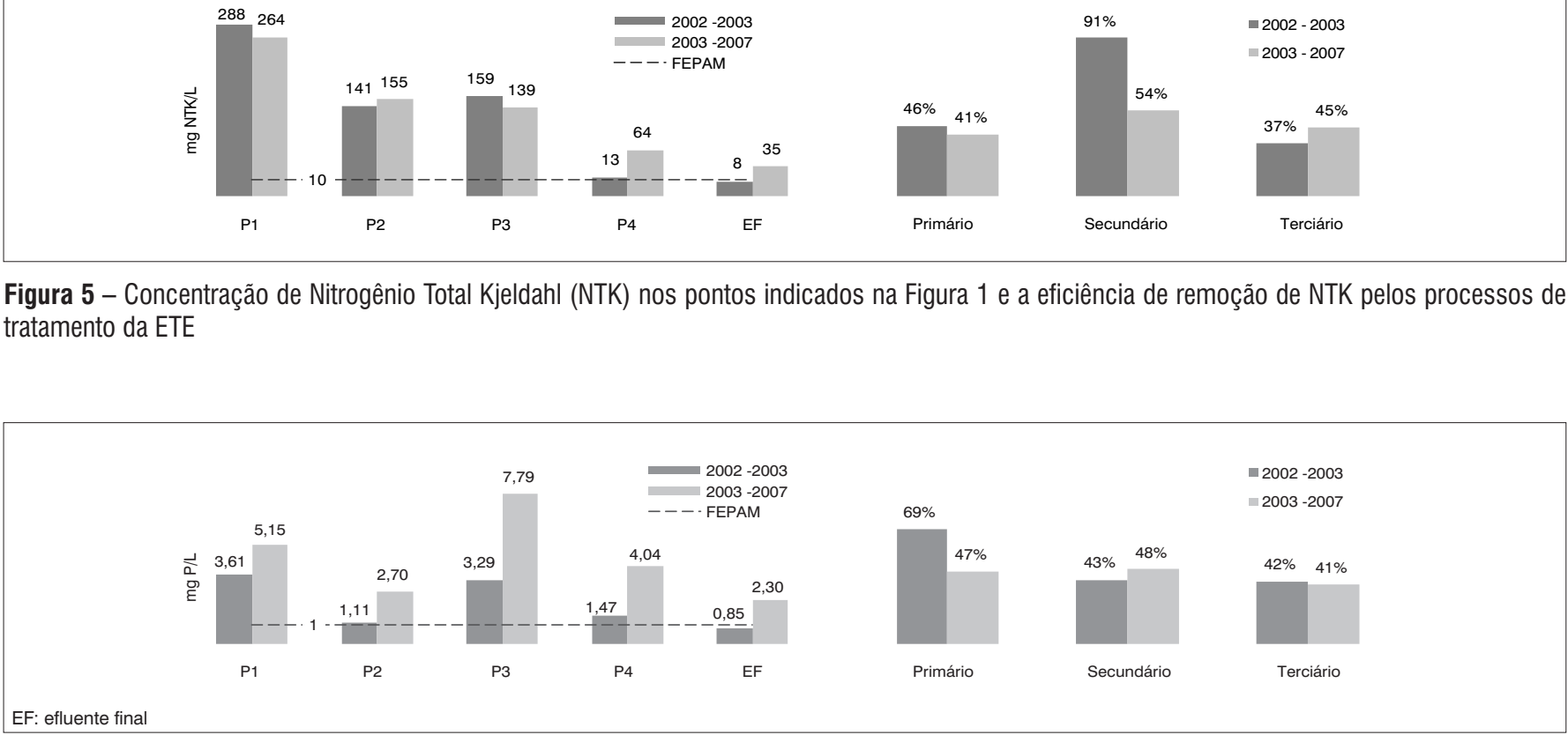

$=2002-2003$

$-2003-2007$
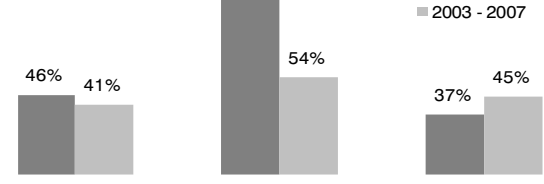

Primário

Secundário

Terciário

Figura 6 - Concentração de P nos pontos indicados na Figura 1 e a eficiência de remoção de P pelos processos de tratamento da ETE

Evidenciado o problema e a data aproximada em que iniciou, avaliou-se a eficiência média de cada processo de tratamento individualmente. A Figura 4, por exemplo, mostra a concentração de $\mathrm{DBO}_{5}$ à montante de cada processo e a eficiência desses processos em removê-la.

No ponto P1, conforme mostra a Figura 4, a $\mathrm{DBO}_{5}$ quase dobrou sua concentração após junho de 2003, indicando o acréscimo da carga orgânica média proveniente dos efluentes do processo fabril. Na Figura 4, observa-se também que o processo secundário de tratamento por lodos ativados sofreu perda de capacidade de remoção de $\mathrm{DBO}_{5}$, a qual caiu de 96 para $76 \%$, enquanto os processos primário e terciário melhoraram a eficiência de remoção desse mesmo contaminante.

A DQO, assim como ocorreu com a $\mathrm{DBO}_{5}$, sofreu acréscimo em P1. Por outro lado, o NTK não teve o mesmo comportamento. A Figura 5 mostra que o NTK sofreu redução de concentração em P3, ou seja, na entrada do processo de lodos ativados, o qual, ainda assim, teve a eficiência de remoção desse poluente reduzida de 91 para $54 \%$.
Diferentemente do NTK, o P sofreu aumento significativo de concentração no efluente fabril (ponto P1). Somado ao aporte desse nutriente no ponto P3, aonde chegavam os efluentes de origem doméstica (sanitários e refeitório), o P teve sua concentração média aumentada em 236\% na entrada do sistema de lodos ativados.

A análise das Figuras 4 a 6 indica que a qualidade do efluente industrial (ponto P1) pode ter sofrido alterações e que o processo de lodos ativados perdera eficiência de remoção de matéria orgânica carbonácea e de NTK a partir de junho de 2003. No entanto, é necessário o conhecimento do histórico de vazões aportando em P3 e dos parâmetros de projeto da ETE para que se possa relacionar a perda de eficiência do processo de lodos ativados com as alterações sofridas na qualidade dos efluentes.

Os dados históricos de vazão da ETE, obtidos a partir de 2003, demonstraram que a vazão média diária de efluente tratado era de $37 \mathrm{~m}^{3}$ e que os valores diários oscilavam entre 30 e $45 \mathrm{~m}^{3}$. Por outro lado, a vazão máxima utilizada no projeto da planta de tratamento foi de 12,45 m³/dia. Embora não se tenha um histórico de vazões da ETE para o período anterior a junho de 2003 , a redução de $10 \%$ ocorrida 
Tabela 3 - Cargas poluentes de DB05, DQ0, NTK e P afluentes ao tratamento secundário (P3)

\begin{tabular}{|c|c|c|c|c|c|}
\hline & & $\mathrm{DBO}_{5}$ & DQO & NTK & $P$ \\
\hline \multirow[t]{3}{*}{ Abril/2002 - maio/2003 } & Concentração média (mg/L) & $1.229,81$ & $2.798,56$ & 159,44 & 3,29 \\
\hline & Vazão ( $\left.\mathrm{m}^{3} / \mathrm{dia}\right)$ & - & - & - & - \\
\hline & Carga (kg/dia) & - & - & - & - \\
\hline \multirow[t]{3}{*}{ Projeto } & Concentração máxima (mg/L) & 1.784 & 4.207 & 98,95 & 19,79 \\
\hline & Vazão ( $\left.\mathrm{m}^{3} / \mathrm{dia}\right)$ & 12,45 & 12,45 & 12,45 & 12,45 \\
\hline & Carga (kg/dia) & 22,21 & 52,38 & 1,23 & 0,25 \\
\hline \multirow[t]{3}{*}{ Junho/2003 - janeiro/2007 } & Concentração média (mg/L) & $1.598,20$ & $3.040,12$ & 138,56 & 7,79 \\
\hline & Vazão (m³/dia) & 37 & 37 & 37 & 37 \\
\hline & Carga (kg/dia) & 59,13 & 112,48 & 5,13 & 0,29 \\
\hline
\end{tabular}

$\mathrm{DBO}_{5}$ : demanda bioquímica de oxigênio; DQO: demanda química de oxigênio; NTK: Nitrogênio Total Kjeldahl; P: fósforo

no quadro de funcionários da empresa a partir de 1997 reforçou a hipótese de que o aumento na geração de efluentes teria ocorrido na área fabril. O efluente industrial, posteriormente a 2003, apresentou um valor médio de $21 \mathrm{~m}^{3} /$ dia, ou seja, somente essa contribuição era $67 \%$ superior à vazão de projeto. Os dados da Tabela 3 apresentam o reflexo do aumento de vazões sobre as cargas afluentes do tratamento secundário.

As concentrações médias afluentes ao tratamento secundário, apresentadas na Tabela 3, com exceção do NTK, não excederam os valores de projeto do sistema de tratamento de efluentes após junho de 2003. No período anterior ao início do problema, os valores médios de NTK já eram superiores ao de projeto, logo, não teriam sido determinantes para a perda de eficiência do processo de lodos ativados. Por outro lado, ao se observar as cargas poluentes aportando a esse processo, percebe-se que são muito superiores ao projetado para a ETE, fato resultante de as vazões reais serem superiores à projetada.

Analisando-se os dados históricos de produção, identificou-se que o início das alterações de qualidade do efluente fabril e o acréscimo de vazões coincidiram com a mudança da lógica de programação da produção. Essa nova lógica aumentou o número de ciclos de lavagem das oito impressoras da planta produtiva, cuja tinta corresponde ao principal integrante do efluente industrial. A cada ciclo de limpeza dessas máquinas, baldes de tinta e demais peças de impressão são trocados e lavados. O aumento da frequência desses ciclos elevou o consumo médio de tintas de $1,67 \mathrm{~g} / \mathrm{m}^{2}$ de papelão impresso para 2,24 g/ $\mathrm{m}^{2}$ e levou altas cargas de $\mathrm{DBO}_{5}$, DQO e P ao ponto P1 da ETE.

\section{Reúso da água}

Após junho de 2003, previamente ao reúso da água, intervenções focadas nos procedimentos e controles operacionais da ETE (BEAL; MONTEGGIA; GIUSTINA, 2006) melhoraram a eficiência do processo de lodos ativados. A segregação dos efluentes industriais da onduladeira e das impressoras, o aumento do controle de $\mathrm{pH}$ no tratamento primário, melhorias no sistema de retrolavagem, a troca mais frequente do material de enchimento dos filtros rápidos e a correção da relação $\mathrm{DBO}_{5}$ :NTK:P por meio da adição de P no ponto P3

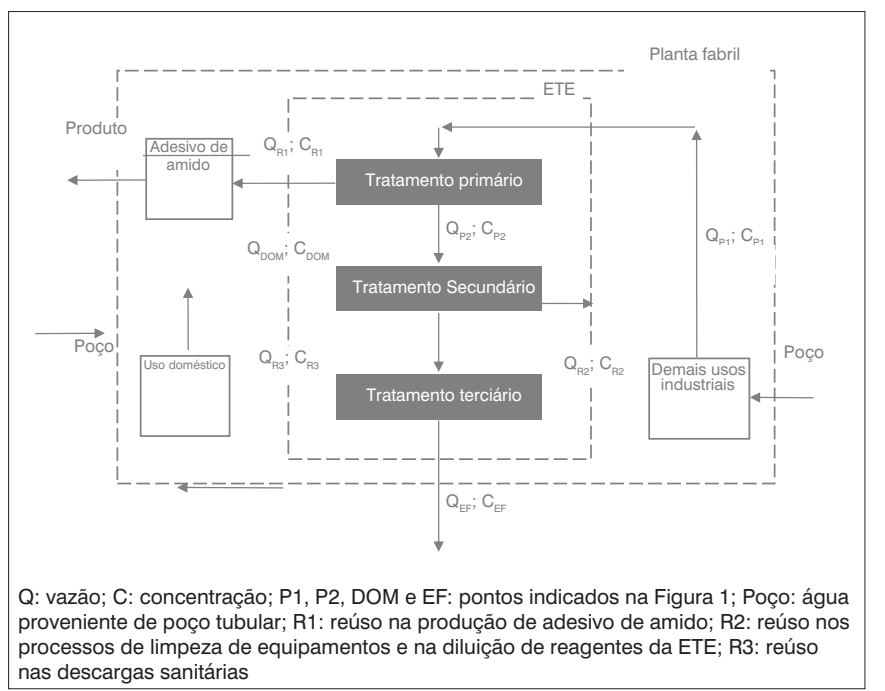

Figura 7 - Fluxograma dos afluentes e efluentes da ETE e da planta fabril

melhoraram o desempenho global da ETE. Contudo, não foram suficientes para atingir a eficiência necessária ao atendimento dos limites de lançamento ao corpo hídrico.

Estando a causa real da perda da eficiência da ETE ligada à sobrecarga do processo de lodos ativados, e considerando-se a capacidade do reúso da água aliviar essa sobrecarga, tal solução passou a ser estudada. O reúso do efluente industrial foi proposto, também, com a finalidade de desenvolver ações visando à sustentabilidade ambiental e à realização de menores intervenções físicas e econômicas, pois a outra alternativa seria a ampliação da ETE.

O efluente primário tratado (ponto P2) foi estudado como fonte de água de reúso nas atividades produtivas, de maneira que fosse incorporado ao produto e não retornasse à ETE. Desse modo, as cargas seriam eliminadas do sistema e não retornariam à ETE, conforme pode ser visto na Figura 7.

Os pontos de consumo, cuja qualidade mínima requerida permite o reúso não-potável da água, são apresentados na Tabela 4. Dentre eles, o uso da água na produção do adesivo de amido (Figura 7) representa a oportunidade de reúso, na qual o efluente de tratamento primário pode ser incorporado ao produto. Os volumes de água consumidos na produção do adesivo, assim como nas demais oportunidades de reúso, foram obtidos por meio dos dados 
históricos coletados nos hidrômetros instalados nas impressoras e na onduladeira. A água consumida nas descargas sanitárias foi estimada considerando-se que cada um dos 480 funcionários acionaria 2 vezes ao dia as válvulas, com vazões de $10 \mathrm{~L} /$ fluxo.

Pesquisas realizadas por Rothstrom e Kohl (2001) e TAPPI (2001) indicam que tanto o efluente bruto dos processos de limpeza das fábricas de embalagens de PO quanto os efluentes de tratamento primário podem ser reusados na produção de adesivo de amido. Contudo, Rothstrom e Kohl (2001) alertam que o reúso de efluente bruto pode ocasionar problemas de qualidade ao adesivo. TAPPI (1997) apresenta um estudo de caso bem sucedido de reúso do efluente de tratamento primário na produção de adesivo. Portanto, essa prática também foi adotada neste trabalho, para que as cargas afluentes ao processo de lodos ativados passassem a ser incorporadas ao produto e não retornassem à ETE. Segundo a Tabela 4, o reúso nas etapas 1 e 2 da produção do adesivo de amido apresenta um consumo potencial de água de $18 \mathrm{~m}^{3} /$ dia.

Com o objetivo de revitalizar a ETE, simularam-se vazões crescentes de reúso na produção de adesivo de amido e o respectivo impacto da redução de carga correspondente no processo de lodos ativados (ponto P3). Para tanto, utilizou-se a Equação 1, e os resultados da simulação sobre as cargas afluentes a P3 encontram-se na Tabela 5.

Tabela 4 - Tipos de uso que aceitam reúso não-potável da água com suas respectivas vazões e destino dos efluentes gerados (vazões médias diárias obtidas a partir de janeiro de 2007)

\begin{tabular}{lcc} 
Tipo de uso & Vazões $\left(\mathrm{m}^{3} / \mathrm{dia}\right)$ & Destino \\
\hline Produção de adesivo 1 & 9 & Produto \\
\hline Produção de adesivo 2 & 9 & Produto \\
\hline Diluições na ETE & 3,5 & P1 da ETE \\
Limpeza da onduladeira & 4 & P1 da ETE \\
Limpeza das impressoras & 10,8 & P1 da ETE \\
Limpeza de baldes e clichês & 2,5 & P1 da ETE \\
Limpezas diversas & 0,2 & P1 da ETE \\
Descargas sanitárias & 9,6 & DOM da ETE \\
Total & 48,6 & \\
\hline
\end{tabular}

ETE: estação de tratamento de efluentes; DOM: efluentes domésticos
$\left(\mathrm{Q}_{\mathrm{P} 2} \times \mathrm{C}_{\mathrm{P} 2}+\mathrm{Q}_{\mathrm{DOM}} \times \mathrm{C}_{\mathrm{DOM}}\right) \div 1000=\mathrm{Carga}_{\mathrm{P} 3}$

Equação 1

onde:

$\mathrm{Q}_{\mathrm{n}}=$ Vazão no ponto "n" indicado na Figura 1 ( $\mathrm{n}=\mathrm{P} 2$ ou DOM);

$\mathrm{C}_{\mathrm{n}}=$ Concentração de poluente $\left(\mathrm{DBO}_{5}, \mathrm{DQO}, \mathrm{N}\right.$ ou $\left.\mathrm{P}\right)$ no ponto "n" indicado na Figura 1 (n = P2 ou DOM);

$\operatorname{Carga}_{\mathrm{P} 3}=$ Carga de poluente na entrada do tratamento secundário (P3)

Ao comparar os dados de carga da Tabela 5 com os dados de carga de projeto apresentados na Tabela 3, percebe-se que o reúso de $18 \mathrm{~m}$ /dia do efluente industrial enquadraria a operação da ETE aos critérios de projeto. A única exceção seria o NTK; contudo, com a flexibilização ocorrida no seu limite máximo de lançamento estabelecido pela FEPAM (SEMA, 2006), passando de $10 \mathrm{mg}$ NTK/L para 20 mg NTK/L, e com a retomada de sua eficiência de remoção no processo de lodos ativados, o problema seria resolvido.

Caracterizado o reúso da água ofertada em P2 como solução de revitalização da ETE, modelaram-se os processos de tratamento de efluentes matematicamente, considerando-se também o ponto EF como fonte de oferta de água de reúso (Figura 7). Esse modelo foi baseado no balanço de cargas da ETE e foi aplicado para determinar como os reúsos apontados na Tabela 4 poderiam afetar o tratamento secundário frente às condições de projeto. As Equações 1 a 8 foram utilizadas para gerar os valores apresentados nas colunas das Tabelas 5 e 6.

$\mathrm{Q}_{P 2}=\mathrm{Q}_{P 1}-\mathrm{Q}_{\mathrm{R} 1}$

Equação 2

$Q_{E F}=\left(Q_{P 2}+Q_{D O M}\right)-\left(Q_{R 2}+Q_{R 3}\right)$

Equação 3

$\mathrm{C}_{R 2}=\mathrm{C}_{R 3}=\mathrm{C}_{\mathrm{EF}}$

Equação 4

$\mathrm{C}_{P 1 n}=\left[\left(\mathrm{Q}_{P 1} \times \mathrm{C}_{P 1}\right)_{A}+\left(\mathrm{Q}_{R 2}+\mathrm{Q}_{R 3}\right)_{n} \times \mathrm{C}_{E F n}\right] \div \mathrm{Q}_{P 1 n} \quad \therefore \quad \mathrm{n}=\mathrm{B} \ldots \mathrm{F}$

Equação 5

Tabela 5 - Simulação das vazões e concentrações afluentes ao sistema de lodos ativados, de origem industrial (P2) e doméstica (D0M), da vazão de reúso (P2) e os respectivos impactos sobre as cargas afluentes ao tratamento secundário

\begin{tabular}{|c|c|c|c|c|c|c|c|c|c|c|c|c|c|c|c|}
\hline \multicolumn{4}{|c|}{$\begin{array}{l}\text { Vazões } \\
\left(\mathrm{m}^{3} / \mathrm{dia}\right)\end{array}$} & \multicolumn{4}{|c|}{$\begin{array}{c}\text { Concentração - P2 } \\
\text { (mg/L) }\end{array}$} & \multicolumn{4}{|c|}{$\begin{array}{c}\text { Concentração - DOM } \\
\text { (mg/L) }\end{array}$} & \multicolumn{4}{|c|}{$\begin{array}{c}\text { Carga - P3 } \\
\text { (kg/dia) }\end{array}$} \\
\hline P2 & DOM & P3 & Reúso & $\mathrm{DBO}_{5}$ & DQO & NTK & $P$ & $\mathrm{DBO}_{5}$ & DQO & NTK & $P$ & $\mathrm{DBO}_{5}$ & DQO & NTK & P \\
\hline 21 & 16 & 37 & 0 & 2,055 & 3,987 & 154,5 & 2,7 & 999 & 1,797 & 117,6 & 14,5 & 59,13 & 112,48 & 5,13 & 0,29 \\
\hline 19 & 16 & 35 & 2 & 2,055 & 3,987 & 154,5 & 2,7 & 999 & 1,797 & 117,6 & 14,5 & 55,02 & 104,51 & 4,82 & 0,28 \\
\hline 17 & 16 & 33 & 4 & 2,055 & 3,987 & 154,5 & 2,7 & 999 & 1,797 & 117,6 & 14,5 & 50,91 & 96,54 & 4,51 & 0,28 \\
\hline 15 & 16 & 31 & 6 & 2,055 & 3,987 & 154,5 & 2,7 & 999 & 1,797 & 117,6 & 14,5 & 46,8 & 88,56 & 4,2 & 0,27 \\
\hline 13 & 16 & 29 & 8 & 2,055 & 3,987 & 154,5 & 2,7 & 999 & 1,797 & 117,6 & 14,5 & 42,69 & 80,59 & 3,89 & 0,27 \\
\hline 11 & 16 & 27 & 10 & 2,055 & 3,987 & 154,5 & 2,7 & 999 & 1,797 & 117,6 & 14,5 & 38,58 & 72,61 & 3,58 & 0,26 \\
\hline 9 & 16 & 25 & 12 & 2,055 & 3,987 & 154,5 & 2,7 & 999 & 1,797 & 117,6 & 14,5 & 34,48 & 64,64 & 3,27 & 0,26 \\
\hline 7 & 16 & 23 & 14 & 2,055 & 3,987 & 154,5 & 2,7 & 999 & 1,797 & 117,6 & 14,5 & 30,37 & 56,66 & 2,96 & 0,25 \\
\hline 5 & 16 & 21 & 16 & 2,055 & 3,987 & 154,5 & 2,7 & 999 & 1,797 & 117,6 & 14,5 & 26,26 & 48,69 & 2,65 & 0,24 \\
\hline 3 & 16 & 19 & 18 & 2,055 & 3,987 & 154,5 & 2,7 & 999 & 1,797 & 117,6 & 14,5 & 22,15 & 40,71 & 2,35 & 0,24 \\
\hline 1 & 16 & 17 & 20 & 2,055 & 3,987 & 154,5 & 2,7 & 999 & 1,797 & 117,6 & 14,5 & 18,04 & 32,74 & 2,04 & 0,23 \\
\hline
\end{tabular}

$\mathrm{DBO}_{5}$ : demanda bioquímica de oxigênio; DQO: demanda química de oxigênio; NTK: Nitrogênio Total Kjeldahl; P: fósforo 
$\mathrm{C}_{P 2 n}=\mathrm{C}_{P 2 A}+\left(\mathrm{C}_{P 1 n}-\mathrm{C}_{P 1 A}\right) \quad \therefore$ quando $\left(\mathrm{Q}_{R 2 n}+\mathrm{Q}_{R 3 n}\right)>\mathrm{Q}_{\mathrm{RIn}} \quad \therefore \quad \mathrm{n}=\mathrm{B} \ldots \mathrm{F}$

Equação 6

$C_{P 2 n}=C_{P 2 A} \quad \therefore \quad$ quando $\left(Q_{R 2 n}+Q_{R 3 n}\right) \leq Q_{R 1 n} \quad \therefore \quad n=B \ldots F$

Equação 7

Carga $=(\mathrm{Q} \times \mathrm{C}) \div 1000$

Equação 8

Os cenários "n" apontados nas Tabelas 6 e 7 representam as etapas da implantação do reúso da água previstas:

- A: sem reúso da água;

- B: reúso apenas na etapa 2 de produção do adesivo de amido. Para esse cenário, estimou-se que a concentração no ponto $\mathrm{EF}\left(\mathrm{C}_{\mathrm{FF}}\right)$ assumiria valores intermediários entre a situação antes e após junho de 2003;

- C: reúso nas etapas 1 e 2 da produção de adesivo de amido. $C_{\mathrm{EF}}$ retomaria os valores encontrados anteriormente a junho de 2003;

- D: idem ao cenário "C", acrescido do reúso na diluição de reagentes na ETE;

- E: idem ao cenário "D", acrescido do reúso na limpeza da onduladeira;

- F: idem ao cenário "E", acrescido do reúso na limpeza das impressoras.

Nas Tabelas 6 e 7, observa-se que a vazão da ETE não seria suficiente para atender todos os reúsos previstos e, por isso, não foi criado um cenário que contemplasse as descargas sanitárias.

Quanto ao comportamento da $\mathrm{DBO}_{5}$, percebe-se que ela retomaria as condições de projeto a partir do cenário "C". No cenário "F", ela ficaria, teoricamente, na situação de projeto (apenas 0,18\% superior).
No caso do NTK, todos os cenários previstos não seriam suficientes para atender às condições projetadas para o sistema de lodos ativados. Ainda assim, a partir do cenário "C", a redução da carga de NTK, devido à incorporação no produto, seria superior a 50\% quando comparada ao cenário "A". Isso, teoricamente, melhoraria a eficiência do tratamento de efluentes, cabendo destacar, também, que a situação prévia a junho de 2003 era mais crítica que as previstas nos cenários de reúso. Por conseguinte, a remoção correspondente de NTK também passaria a atender aos limites de emissão, conforme ocorria anteriormente a junho de 2003.

Nos cenários simulados, o comportamento da DQO e do P foram similares ao da $\mathrm{DBO}_{5}$, ou seja, desde o cenário "C", todas as cargas afluentes ao tratamento secundário respeitaram os limites máximos projetados para os respectivos parâmetros.

Visto que o cenário "C" resolveria a situação do sistema de tratamento de efluentes e representaria a opção de menor custo, foi adotado por meio da conversão do tanque pulmão da Figura 2 em reservatório de água de reúso.

Inicialmente, apenas o cenário "B" foi implantado para que os reflexos do reúso sobre a qualidade do adesivo pudessem ser estudados. Acompanhou-se a viscosidade e o ponto gel do adesivo (PERKINS; SCHNELL; BRITTAIN, 2000) e a qualidade da adesão das folhas que constituíam as chapas de PO. Adotou-se o controle de $\mathrm{pH}$ da água de reúso e instalou-se um misturador no reservatório dessa água para atenuar possíveis alterações de qualidade. A adição de biocida às bateladas de adesivo complementou as medidas de controle da oscilação da viscosidade e do ponto gel diagnosticada durante o cenário "B".

Tabela 6 - Simulação da carga de $\mathrm{DBO}_{5}$ afluente ao tratamento secundário após o reúso da água

\begin{tabular}{|c|c|c|c|c|c|c|c|c|c|c|c|c|c|c|c|c|}
\hline \multirow[b]{2}{*}{$n$} & \multicolumn{7}{|c|}{ Vazão $\left(\mathrm{m}^{3} / \mathrm{dia}^{-1}\right)$} & \multicolumn{4}{|c|}{$\mathrm{DBO}_{5}\left(\mathrm{mg} / \mathrm{L}^{-1}\right)$} & \multicolumn{5}{|c|}{ Carga $\mathrm{DBO}_{5}\left(\mathrm{~kg} / \mathrm{dia}^{-1}\right)$} \\
\hline & $Q_{P 1}$ & $Q_{\mathrm{P} 2}$ & $Q_{\text {DоM }}$ & $Q_{R 1}$ & $Q_{R 2}$ & $Q_{R 3}$ & $Q_{\mathrm{EF}}$ & $\mathrm{C}_{\mathrm{P} 1}$ & $\mathrm{C}_{\mathrm{P} 2}$ & $\mathrm{C}_{\text {Dом }}$ & $\mathrm{C}_{\mathrm{EF}}$ & P1 & P2 & DOM & P3 & Projeto \\
\hline A & 21 & 21 & 16 & 0 & 0 & 0 & 37 & 8,147 & 2,055 & 999 & 163 & 171,1 & 43,2 & 16 & 59,14 & \\
\hline B & 21 & 12 & 16 & 9 & 0 & 0 & 28 & 8,147 & 2,055 & 999 & 101 & 171,1 & 24,7 & 16 & 40,64 & \\
\hline $\mathrm{C}$ & 21 & 3 & 16 & 18 & 0 & 0 & 19 & 8,147 & 2,055 & 999 & 39 & 171,1 & 6,2 & 16 & 22,15 & \\
\hline D & 21 & 3 & 16 & 18 & 3,5 & 0 & 15,5 & 8,154 & 2,055 & 999 & 39 & 171,2 & 6,2 & 16 & 22,15 & 2,21 \\
\hline$E$ & 21 & 3 & 16 & 18 & 7,5 & 0 & 11,5 & 8,161 & 2,055 & 999 & 39 & 171,4 & 6,2 & 16 & 22,15 & \\
\hline $\mathrm{F}$ & 21 & 3 & 16 & 18 & 19 & 0 & 0 & 8,182 & 2.09 & 999 & 39 & 171,8 & 6.3 & 16 & 22,25 & \\
\hline
\end{tabular}

Tabela 7 - Simulação da carga de NTK afluente ao tratamento secundário após o reúso da água

\begin{tabular}{|c|c|c|c|c|c|c|c|c|c|c|c|c|c|c|c|c|}
\hline \multirow[b]{2}{*}{$n$} & \multicolumn{7}{|c|}{ Vazão $\left(\mathrm{m}^{3} / \mathrm{dia}^{-1}\right)$} & \multicolumn{4}{|c|}{ NTK (mg/L-1) } & \multicolumn{5}{|c|}{ Carga NTK $\left(\mathrm{kg} / \mathrm{dia}^{-1}\right)$} \\
\hline & $Q_{P 1}$ & $Q_{P 2}$ & $\mathbf{Q}_{\text {Dом }}$ & $Q_{R 1}$ & $\mathrm{Q}_{\mathrm{R} 2}$ & $Q_{R 3}$ & $Q_{E F}$ & $\mathrm{C}_{\mathrm{P} 1}$ & $\mathrm{C}_{\mathrm{P} 2}$ & $\mathrm{C}_{\text {DоM }}$ & $\mathrm{C}_{\mathrm{EF}}$ & P1 & P2 & DOM & P3 & Projeto \\
\hline A & 21 & 21 & 16 & 0 & 0 & 0 & 37 & 264 & 155 & 118 & 35 & 5,54 & 3,24 & 1,88 & 5,13 & \\
\hline B & 21 & 12 & 16 & 9 & 0 & 0 & 28 & 264 & 155 & 118 & 21 & 5,54 & 1,85 & 1,88 & 3,74 & \\
\hline C & 21 & 3 & 16 & 18 & 0 & 0 & 19 & 264 & 155 & 118 & 8 & 5,54 & 0,46 & 1,88 & 2,35 & \\
\hline D & 21 & 3 & 16 & 18 & 3,5 & 0 & 15,5 & 265 & 155 & 118 & 8 & 5,57 & 0,46 & 1,88 & 2,35 & 1,23 \\
\hline E & 21 & 3 & 16 & 18 & 7,5 & 0 & 11,5 & 267 & 155 & 118 & 8 & 5,6 & 0,46 & 1,88 & 2,35 & \\
\hline$F$ & 21 & 3 & 16 & 18 & 19 & 0 & 0 & 271 & 161 & 118 & 8 & 5,69 & 0,48 & 1,88 & 2,37 & \\
\hline
\end{tabular}




\section{Diagnóstico final}

O cenário "B" foi completamente implantado a partir de julho de 2007 e o cenário "C", a partir de janeiro de 2009. A Figura 8 ilustra o comportamento das vazões: enviadas ao corpo receptor (EF), de reúso no adesivo (R1) e total tratada na ETE (P1 + DOM).

A redução de vazão lançada ao corpo receptor, considerandose o valor médio de $37 \mathrm{~m}^{3} /$ dia, foi de $56 \%$, visto que, após a implantação do cenário "C", esta foi reduzida para 16,27 m²/dia. Quando se considera a vazão máxima de $45,5 \mathrm{~m}^{3} /$ dia, a redução é de 64,24\%. Embora o cenário final de reúso tenha sido implantado, ainda há um potencial de 2,5 a $3 \mathrm{~m}^{3} /$ dia a ser reusado na fabricação do adesivo e que está usando água de poço. Isso se deve a um conservadorismo do setor de produção quanto a uma das formulações do adesivo que necessita de maior capacidade de adesão

A análise da eficiência da ETE teve que ser realizada por meio das características do efluente do tratamento secundário apenas. A conversão do tanque pulmão em reservatório de água de reúso, embora tenha proporcionado o melhor aproveitamento do espaço físico limitado da ETE e tenha reduzido custos com a construção

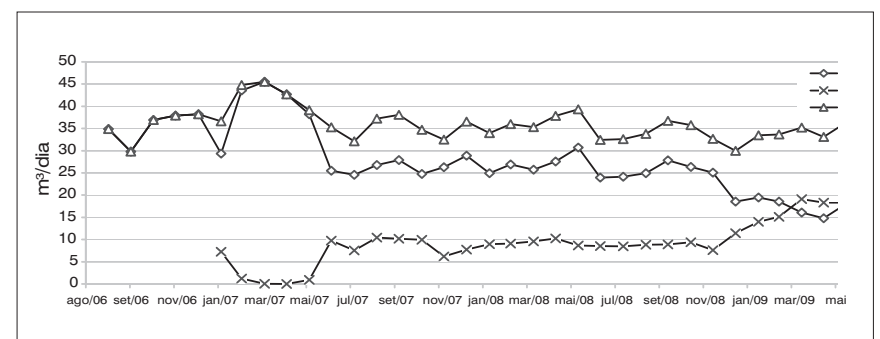

Figura 8 - Comportamento histórico das vazões afluentes e efluentes à ETE; EF: efluente final; R1: reúso na produção de adesivo de amido; P1: início do tratamento primário; DOM: efluente doméstico de um novo reservatório, levou à perda da equalização de concentração de poluentes originados nos processos industriais, sanitários e refeitório. Mesmo tendo-se perdido esse ponto de referência para que se pudesse calcular a eficiência do tratamento secundário, realizou-se a análise estatística (teste de hipóteses por meio do cálculo de Student) sobre a concentração de poluentes remanescentes no efluente desse tratamento (ponto P4 da Figura 1). Os testes de hipótese verificaram se houve diferença significativa entre essas concentrações para os quatro períodos que este estudo compreendeu:

- Período 1: antes de junho de 2003;

- Período 2: entre junho de 2003 e janeiro de 2007 (perda da eficiência da ETE);

- Período 3: entre julho de 2007 e dezembro de 2008 (cenário "B" de reúso);

- Período 4: entre de janeiro e agosto de 2009 (cenário "C" de reúso).

A Tabela 8 mostra o comportamento estatístico e os testes de hipótese para a $\mathrm{DBO}_{5}$ em cada um dos períodos indicados.

Os testes estatísticos para a $\mathrm{DBO}_{5}$ indicam que houve diferença significativa entre as médias nas três transições entre períodos, pois $\left|t_{\text {calculado }}\right|>t_{\text {crítico }}$, com $95 \%$ de certeza. Os valores médios de $\mathrm{DBO}_{5}$ observados no efluente convergiram para valores abaixo daqueles exigidos pelo órgão ambiental (135 mg/L), mesmo antes de receberem o tratamento terciário. Além disso, o desvio padrão também é decrescente e a situação do sistema de lodos ativados direciona-se à realidade existente no período 1 . O mesmo comportamento foi observado para a DQO, sendo que, após o cenário "C" ser implantado, as concentrações médias desse parâmetro e da $\mathrm{DBO}_{5}$ no ponto EF foram reduzidas para 128 e $28,3 \mathrm{mg} / \mathrm{L}$, respectivamente.

Tabela 8 - Evolução da concentração de demanda bioquímica de oxigênio $\left(\mathrm{DBO}_{5}\right)$ no efluente do tratamento secundário

\begin{tabular}{|c|c|c|c|c|}
\hline & Período 1 & Período 2 & Período 3 & Período 4 \\
\hline Média (mg/L) & 48,88 & 387,25 & 131,74 & 46,49 \\
\hline Desvio padrão (mg/L) & 14,35 & 432,35 & 64,94 & 22,12 \\
\hline Número de dados & 16 & 72 & 36 & 7 \\
\hline$t_{\text {calculado }}\left(\right.$ Período $_{(n-1)}$ e Período $) ; \alpha=0,05$ & & $-6,63$ & 4,91 & 6,23 \\
\hline $\mathrm{t}_{\text {critico }}$ (unicaudal) $\left(\right.$ Período $_{(\mathrm{n}-1)}$ e Período $) ; \alpha=0,05$ & & 1,67 & 1,67 & 1,7 \\
\hline
\end{tabular}

Tabela 9 - Evolução da concentração de Nitrogênio Total Kjeldahl (NTK) no efluente do tratamento secundário

\begin{tabular}{lcccc} 
& Período 1 & Período 2 & Período 3 & Período 4 \\
Média $(\mathrm{mg} / \mathrm{L})$ & 13,15 & 63,99 & 32,09 & 11,51 \\
\hline Desvio padrão $(\mathrm{mg} / \mathrm{L})$ & 6,55 & 49,11 & 37,11 & 9,45 \\
Número de dados & 16 & 72 & 36 & 7 \\
$\mathrm{t}_{\text {calculado }}$ (Período \\
$\mathrm{t}_{\text {crítico }}$ (unicaudal)
\end{tabular}


Os valores apresentados para NTK na Tabela 9 demonstram que esse parâmetro também convergiu para a situação prévia à perda de eficiência da ETE, chegando a ser inferior àquele obtido no período 1. Logo, assim como ocorreu para a $\mathrm{DBO}_{5}$ e para a DQO, os valores médios de NTK passaram a atender os limites de emissão antes de o efluente receber o tratamento terciário. Após o cenário "C" do reúso, o NTK médio foi reduzido para 7,99 mg/L no ponto EF.

O P, por outro lado, teve sua concentração aumentada na saída do processo de lodos ativados após a implantação do cenário " $\mathrm{C}$ " de reúso. Isso se deveu ao aumento da disponibilidade desse nutriente na alimentação do tratamento secundário, pois o efluente industrial tratado primariamente, reusado na produção de adesivo, apresentava alta concentração de $\mathrm{DBO}_{5}$ e de NTK, porém era pobre em P. Desse modo, o efluente de origem doméstica, rico em P, passou a alimentar o sistema de lodos ativados em uma relação aproximada de 3 a 4 kg P/100 kg DBO, enquanto Von Sperling (1997) recomenda 0,5 a 0,6 $\mathrm{kg} \mathrm{P} / 100 \mathrm{~kg} \mathrm{DBO}_{5}$ para projeto de processos por aeração prolongada. Por esse motivo, a concentração média de P em P4 da Figura 1 passou de 1,93 mg/L, no período 3, para 7,03 mg/L no período $4 \mathrm{e}$, consequentemente, deixou de atender o limite de emissão no ponto $\mathrm{EF}(5,92 \mathrm{mg} / \mathrm{L})$.

A solução de controle desse parâmetro passa pelo acréscimo de $\mathrm{DBO}_{5}$ ao processo de lodos ativados, pela inclusão de uma etapa de tratamento ao processo biológico, pela precipitação química do $\mathrm{P}$ ou, ainda, pelo próprio reúso da água. A Tabela 4 mostra que existe demanda por água de reúso para os processos de limpeza industriais, que poderiam consumir todo o efluente de tratamento terciário, eliminando o seu lançamento ao corpo receptor. Ou seja, o P deixaria de ser lançado ao meio ambiente, eliminando o problema com seu limite de lançamento.

\section{Conclusão}

Este trabalho mostrou que o reúso da água em uma indústria pode ser utilizado como ferramenta eficaz de revitalização de estações de tratamento de efluentes. A ETE estudada, por exemplo, teve a vazão média afluente ao processo de lodos ativados reduzida em mais de $50 \%$, passando a tratar um efluente de origem predominantemente doméstico, ou seja, mais adequado ao tipo de processo.

Muito embora o P tenha saído do controle e extrapolado o limite de emissão da FEPAM, após o cenário "C", o reúso permanece sendo uma medida de revitalização de ETE's. No caso estudado, a carga de $\mathrm{DBO}_{5}$ afluente ao processo de lodos ativados foi excessivamente reduzida, provocando um desbalanceamento na relação $\mathrm{DBO}_{5} / \mathrm{P}$. Isso não significa que o reúso da água diminuiu a eficiência de remoção de $\mathrm{P}$ pela ETE, mas sim que ela teve ampliada a sua capacidade de tratar $\mathrm{DBO}_{5}$ por meio do processo de lodos ativados.

Além do prolongamento da vida útil da ETE, o reúso da água beneficiou o meio ambiente por meio da redução das cargas poluentes emitidas ao corpo receptor e dos volumes de água captados no meio ambiente. O efluente tratado, enviado ao meio ambiente, que chegou a $45 \mathrm{~m}^{3} /$ dia antes do reúso, caiu para menos de 20 $\mathrm{m}^{3} / \mathrm{dia}$, assim como ocorreu com as respectivas cargas poluentes associadas. Por sua vez, o volume de água usado na produção de adesivo de amido foi substituído por água de reúso quase que integralmente, reduzindo a adução de água de fontes naturais entre 15 e $20 \mathrm{~m}^{3} / \mathrm{dia}$.

Tendo em vista os benefícios apresentados por meio deste estudo de caso, pode-se estabelecer que, antes de utilizar técnicas complementares de tratamento de efluentes na otimização de estações de tratamento, é importante avaliar possíveis reúsos de efluentes brutos ou de efluentes que receberam apenas tratamento parcial.

\section{Referências}

APHA, AWWA, WEF. Standard methods for the examination of water and wastewater. 21. ed. Washington, DC: APHA, 2005.

BEAL, L.L.; MONTEGGIA, L.O.; GIUSTINA, S.V.D. Otimização de uma estação de tratamento de efluentes de uma indústria de embalagens de papel. Revista Engenharia Sanitária e Ambiental, v. 11, n. 3, p. 283-289, 2006.

BRASIL. Presidência da República. Casa Civil. Lei n. 9.433, de 8 de Janeiro de 1997. 1997. Disponível em: <http://www.planalto.gov.br/ ccivil 03/Leis/L9433.htm>. Acesso em: 5 maio 2009.

CONAMA (Conselho Nacional Do Meio Ambiente). 2005. Resolução $n$. 357, de 17 de março de 2005. Disponível em: < www.mma.gov.br/port/ conama/res/res05/res35705.pdf > . Acesso em 12 ago. 2009.
COSTA NETO, P.L.O. Estatística. 2. ed. São Paulo: Edgard Blucher, 2002.

CROOK, J. Critérios de qualidade da água para reúso. Revista DAE, v. 53, n. 174, p. 10-18, 1993.

EPA (Environmental Protection Agency). Guidelines for water reuse. EPA 645-R-04-108. Washington, DC: United States Environmental Protection Agency, 2004.

FEPAM (Fundação Estadual de Proteção Ambiental Henrique Luis Roessler). 1989. Portaria $n^{\circ}$ 05/89, de 16 de março de 1989. Disponível em: < http://www.fepam.rs.gov.br/licenciamento/Area4/18_02.asp?co $\mathrm{mp}=1 \&$ tipo $=5 \&$ num $=5 \& a n o=1989 \& \mathrm{key}=>$. Acesso em: 9 jun. 2010. MIERZWA, J.C.; HESPANHOL, I. Água na indústria: uso racional e reúso. São Paulo: Oficina de Textos, 2005 
PERKINS, S.R.; SCHNELL, P.G.; BRITTAIN, J.A. The corrugated containers manufacturing process. Atlanta: TAPPI Press, 2000.

ROTHSTROM, C.; KOHL, J. Potential impact of waste water on starch adhesive. . 2001. Disponível em: <http://www.wwenvironmental.com/ article starch english.php>. Acesso em: 15 out. 2004.

RULKENS, W.H. Sustainable development in industry by closing water loops: technological aspects and expected future developments. In: MOURNIGHAN, R. et al. Chemistry for the Protection of the Environment 4 New York: Springer, 2005, p. 223-254 (Environmental Science Research, v. 59).

SAUTCHÚK, C.A. Diretrizes básicas para implantação de programas de conservação de água em edificações. Dissertação (Mestrado em Engenharia Urbana e Construções Civis), Universidade de São Paulo, São Paulo, 2004.

SEMA (Secretaria Estadual do Meio Ambiente do Rio Grande do Sul). 2006. Resolução Consema $n^{\circ}$ 128/2006. Disponível em: < http://www. sema.rs.gov.br/sema/html/pdf/Resolucao128Efluentes.pdf>. Acesso em: 5 maio 2009.
TAPPI (Technical Association for the Worldwide Pulp, Paper, and Converting Industry). 2001. Using washup water as the vehicle in starch based corrugating adhesive. Technical Information Paper TIP 0304-44. Disponível em: < http://www.standardsstore.com/ RecordDetail.aspx?sku=TIP +0304-44\%3A2001 > . Acesso em: 21 jun. 2010

Recycling treated process wastewater in starch adhesive at a corrugated packaging plant. Environmental Conference Proceedings. Atlanta: TAPPI Press, 1997.

TCHOBANOGLOUS, G.; BURTON, F.L. Wastewater engineering: treatment, disposal, and reuse. 4. ed. Nova York: McGraw-Hill, 2003.

VON SPERLING, M. Princípios do tratamento biológico de águas residuárias: lodos ativados. v. 4. Belo Horizonte: DESA/UFMG, 1997.

WENZEL, H.; KNUDSEN, H.H. Water savings and reuse in the textile industry. In: OMELCHENKO, A.; PIVOVAROV, A. A.; SWINDALL, W. J. (Ed.). Modern tools and methods of water treatment for improving living standards. Amsterdam: Springer Netherlands, 2005, p. 169-189. 